\title{
Effect of oral capsule of Peganum harmala seeds on bone density in menopausal women prone to osteoporosis
}

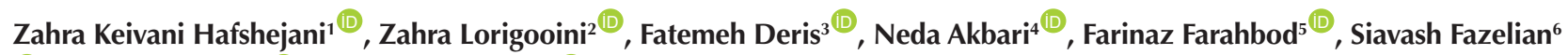 \\ (D) Fatemeh Moradi $^{\mathbb{D}}$, Morteza Dehghan ${ }^{8^{*}} \mathbb{D}$
}

'Department of Nursing, Research Expert, Research and Technology Division, Shahrekord University of Medical Sciences, Shahrekord, Iran

${ }^{2}$ Medical Plants Research Center, Basic Health Sciences Institute, Shahrekord University of Medical Sciences, Shahrekord, Iran ${ }^{3}$ Department of Epidemiology and Biostatistics, School of Health, Shahrekord University of Medical Sciences, Shahrekord, Iran

${ }^{4}$ Shahrekord University of Medical Sciences, Shahrekord, Iran

${ }^{5}$ Department of Obstetrics and Gynecology, Isfahan University of Medical Sciences, Isfahan, Iran

${ }^{6}$ Clinical Research Development Unit, Ayatollah Kashani Hospital, Shahrekord University of Medical Sciences, Shahrekord, Iran

${ }^{7}$ Department of Community Nutrition, School of Nutrition and Food Science, Isfahan University of Medical Sciences, Isfahan, Iran

${ }^{8}$ Clinical Research Development Unit, Ayatollah Kashani Hospital, Shahrekord University of Medical Sciences, Shahrekord, Iran

*Corresponding Author: Morteza Dehghan, Department of Orthopedic Surgery, Shahrekord University of Medical Sciences, Shahrekord, Iran. Tel: +98383 3338891; Email: dehghan_mortaza@yahoo.com

\begin{abstract}
Background and aims: Osteoporosis is one of the most common metabolic bone diseases with systemic involvement of the body skeleton. The Peganum harmala seed contains high amounts of carboline alkaloids, which have been shown to have positive effects on bone formation in animal studies. In the present study, the effect of an oral capsule of $P$. harmala seed on bone density was evaluated in menopausal women prone to osteoporosis.

Methods: In this randomized controlled clinical trial, 100 women referring to the orthopedic clinic with a diagnosis of osteoporosis were included and divided into the intervention group treated with calcium D (500 mg) twice a day, Osteofos (70 mg) per week, and P. harmala $(500 \mathrm{mg})$ twice-a-day, and the control group treated with calcium D and Osteofos. Before and three months after the intervention, patients were evaluated for osteoporosis using bone densitometry. Finally, independent t-test, paired t-test, and repeated measures ANOVA were used for statistical analysis.

Results: The mean bone mineral density (BMD) of the femur before and after the intervention showed significant improvements in the intervention and control groups $(P<0.001)$. The mean differences in BMD before and after the intervention were significant in both control and intervention groups with higher improvements in the intervention group $(P<0.001)$. Although the mean BMD of the spine before the intervention was not significantly different between the two groups $(P=0.167)$, it was better in the intervention group after the intervention $(P=0.030)$.

Conclusion: The findings of the present study confirmed the beneficial effects of $P$. harmala on osteoporosis while the lack of any changes in liver enzymes.

Keywords: Peganum harmala, Bone mineral density, Osteoporosis, Liver enzyme, Calcium, Vitamin D
\end{abstract}

Received: 2 November 2020, Accepted: 21 June 2021, ePublished: 29 September 2021

Introduction

Bone hemostasis in the body is regulated with osteoclasts and osteogenesis by bone absorption and osteoblastic cells, respectively (1). Osteoclasts are produced from blood monocytes and are responsible for decomposing bone matters during osteogenesis (2). Osteoclasts and osteoblasts have exactly reverse roles (3). Excessive bone absorption by osteoclasts plays a role in the pathogenesis of multiple bone diseases such as osteoporosis, hypercalcemia, rheumatoid arthritis, periodontitis, and Paget's disease (4). Osteoporosis, according to the definition of the National Association of Health, is a skeletal disorder that occurs more often in the elderly (5), and reducing bone strength and putting the person at the risk of fracture are among its obvious features (6). Osteoporosis is the most common pathologic cause associated with skeletal weakness and metabolic disease of the bone, which is associated with bone loss and finally

(C) 2021 The Author(s); Published by Shahrekord University of Medical Sciences. This is an open-access article distributed under the terms of the Creative Commons Attribution License (http://creativecommons.org/licenses/by/4.0), which permits unrestricted use, distribution, and reproduction in any medium, provided the original work is properly cited. 
leads to fracture risk (7).

The process is so slow and gradual that the person does not feel any warning signs until the occurrence of the first fracture (8). Therefore, the importance of osteoporosis is associated with the increased femur, pelvic and spinal fractures, which lead to increased mortality and subsequent increases in costs (9). Therefore, it is believed that the complications of this disease are more precarious than the disease, especially fractures, which are the main factor affecting the quality of life (10).

In the United States, there are 1.5 million osteoporotic fractures per year, of which 700000, 250000, 250000, and 300000 cases are found in the vertebrae, the radius, the pelvis, and other bones, respectively (11). Reduced bone density and the resulting osteoporosis in women are a known phenomenon, and the fractures due to this complication are among the main causes of mortality in older people, especially postmenopausal women. In menopause women, due to estrogen deficiency, the increased activity of osteoclasts and the rate of bone loss, if preventive action is not taken, lead to osteopenia, progressing to osteoporosis $(12,13)$.

Many studies have investigated the beneficial effects of various treatments on this disabling disease, but the lack of acceptance of patients and the side effects of drugs are among the problems that are not ignorable (14). Recently, the therapeutic effects of medicinal plants have been significantly considered, and the positive effects of some medicinal plants on osteoporosis have been proved as well (15). Some plants contain phytoestrogens and have functions similar to estrogen, inhibiting osteoporosis (16). Peganum harmala is one of the plants that has been considered in Iranian traditional medicine. Various alkaloids existing in this plant have extensive pharmacological effects such as antispasmodic $(17,18)$, anti-cancer, anti-depressant $(19,20)$, and antibacterial properties (21). They also can inhibit monoamine oxidase (22), bind to different types of receptors such as 5-TH and benzodiazepine receptors (20). They can improve benign prostatic hypertrophy symptoms (23) and the immune system (24). B-carboline alkaloids increase the growth and differentiation of bone and cartilage cells in cells and rats $(25,26)$. Nonetheless, more studies are needed in this regard since no study has so far focused on osteoporosis in menopausal women. Therefore, the present study aimed to evaluate the effect of an oral capsule of $P$. harmala seeds on bone mineral density (BMD) in postmenopausal women with osteoporosis.

\section{Methods}

\section{Participants}

The trial was a randomized clinical trial study with 100 osteoporotic patients diagnosed with BMD. The criteria for including the trial were no digestive disturbance disorders, no thyroid, renal and hepatic diseases, and no psychiatric disorders. On the other hand, the exclusion criteria included drug allergy, restlessness, convulsion, and mental disorders. Each group of 50 patients was determined using the following formula:

$$
\left.n=\frac{z_{\left(1-\frac{\alpha}{2}\right)}+z_{(1-\beta)}}{d}\right)^{2} \mathrm{n}=50, \mathrm{~d}=0.41 .96=\mathrm{Z}_{(1-\alpha / 2)}, 0.84=\mathrm{Z}_{(1-\beta)}
$$

Study design, intervention, and randomization

Patients were selected by convenience sampling and randomly assigned to the two groups using Random Allocation Software. Random allocation was performed by a person who had no role in any procedures of the study (Figure 1). The first group (intervention group) received capsules containing $P$. harmala $(500 \mathrm{mg})$ twice a day for 3 months in addition to routine drugs (calcium $500 \mathrm{mg}$ twice a day was produced by Tehran Chemie Pharmaceutical Company, alendronate sodium 70 mg or Osteofos once per week produced by Alborzdarou Pharmaceutical Company). The second group (control group) received routine drugs with the same dose. Participants were requested not to change their food intake and physical activity during the intervention.

The inclusion criteria were postmenopausal women who, according to the World Health Organization (WHO), had at least 12 months of menstruation and osteoporosis with a T-score of $\leq-2.5$ in bone densitometry. According to the WHO definition, osteoporosis in postmenopausal women based on densitometry is a BMD reduction of 2.5 or greater than the standard deviation under the mean value for young adults (T-score $\leq-2.5$ ). In this definition, $-2.5 \leq \mathrm{T}$-score $<-1$ is considered osteopenia while T-score $\geq-1$ is considered normal (27).

Exclusion criteria included pregnancy, breastfeeding, smoking, drinking alcohol, other hormonal disorders, and use of hormones or drugs with a negative or positive effect on bone metabolism (e.g., estrogens and bisphosphates) in the past year. Other criteria were the lack of volunteering to participate in the study, allergy to drugs, certain complications such as hallucinations, confusion, and numbness, nausea, vomiting, restlessness, seizure, disorders of intestinal absorption, and thyroid, kidney, liver disorders.

After the botanist approval of the Medical Plants Research Center in Shahrekord University of Medical Science, $P$. harmala seed $(500 \mathrm{mg}$ ) was prepared in the form of capsules. Study objectives and data confidentiality were explained to the participants, and then informed consent was obtained from them for participation in the study.

However, due to the possible hepatotoxic effects of $P$. harmala, liver factors such as aspartate aminotransferase (AST) and alanine aminotransferase (ALT) were checked in all patients before treatment, as well as in the first, second, and third month after the treatment.

\section{Bone Densitometry Assessment}

The dual X-ray absorption was used to perform bone densitometry reported as standardized values called Tand Z-scores $(28,29)$. In this procedure, two X-ray sources 


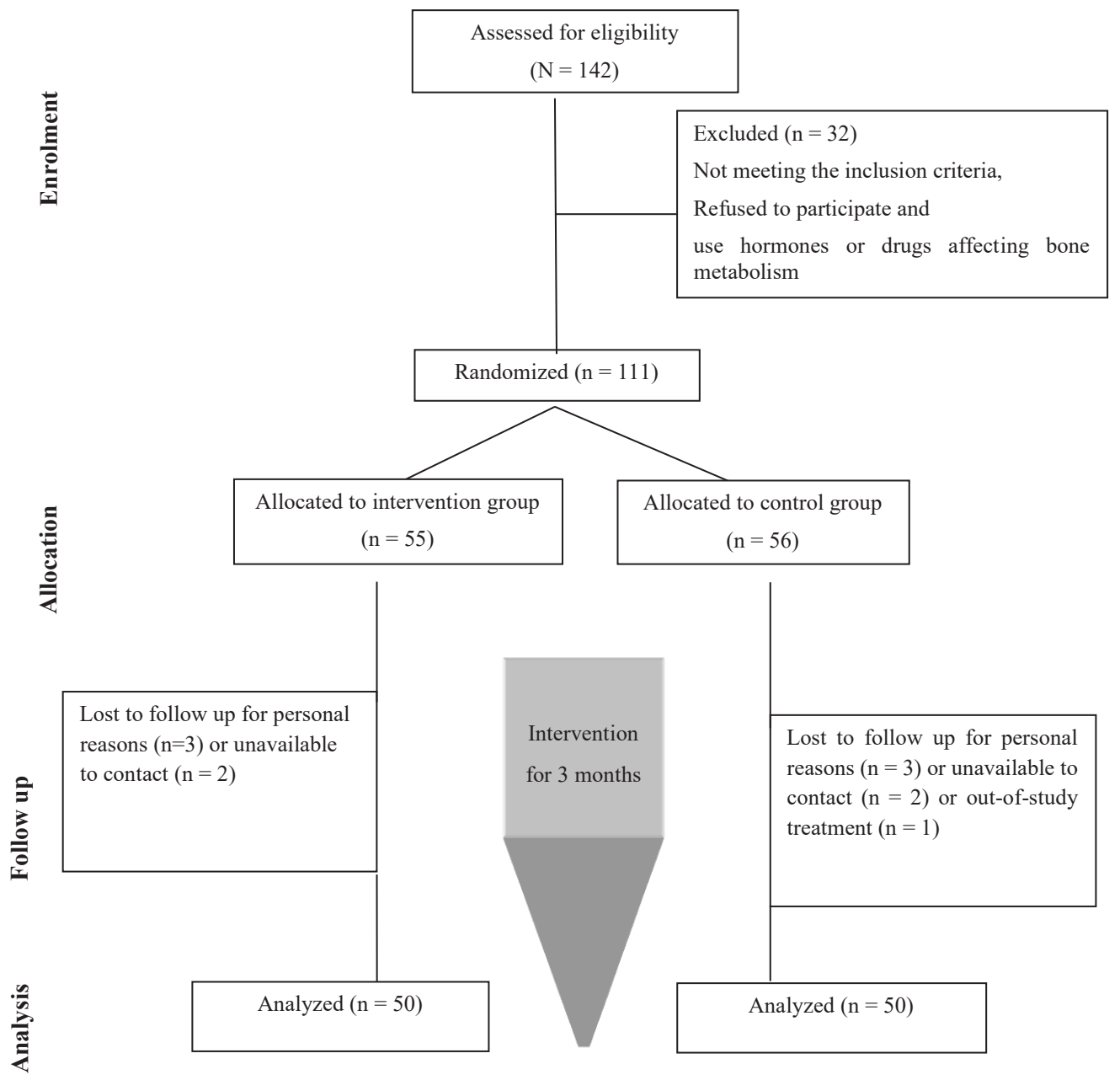

Figure 1. Algorithm of study participants in the two groups.

are sent to the bone to measure the density of the spine, hip, or forearm. Two sources of X-rays are applied to assure accurate measurement. The femur and spine bones were examined in this study. The WHO classification of BMD according to the t-score (30) was normal (-1, 0 , or greater in the $t$-score), osteopenia $(-1,0$, or greater in the $\mathrm{t}$-score), osteoporosis $(-2.5$ or less in the $\mathrm{t}$-score), and severe osteoporosis $(-2.5$ or less in the $t$-score with fracture). BMD was measured at the beginning and end of the study (30).

\section{Statistical Analysis}

Data were entered into SPSS software (version 18) and analyzed by descriptive (Mean and standard deviation) and analytical (independent $t$ test, paired $t$ test, and repeated measures ANOVA with post hoc Tukey's test) statistics, and $P<0.05$ was considered as the significance level.

\section{Results}

The mean age was not significantly different between the intervention $(59.02 \pm 10.49)$ and control (59.06 \pm 9.71$)$ groups $(P=0.984)$. The mean $\mathrm{BMD}$ of the femur before treatment were not significantly different in the intervention and control group $(P=0.927)$ and the mean $\mathrm{BMD}$ of the femur after treatment showed no significant difference in the control group $(P=0.181)$, but a significant decrease was observed in the mean BMD of the femur in each of the intervention and control groups $(P<0.001)$. In general, the mean of changes in the BMD of the femur was significantly higher in the intervention group $(-0.37)$ compared to the control group $(-0.24)$ before and after the treatment $(P<0.001$, Table 1$)$.

Conversely, the mean BMD of the spinal cord before the treatment were not significantly different in the intervention and control groups $(P=0.167)$ while the $\mathrm{BMD}$ of the spinal cord was significantly lower in the intervention group after the treatment in comparison with the control group $(P=0.030)$. Based on the results, a significant decrease was found in the mean BMD of the spinal cord in each of the intervention and control groups $(P<0.001)$. In general, the mean of changes in BMD of the spinal cord before and after treatment in the intervention group $(-0.44)$ is significantly higher than the control group $(-0.22)(P<0.001$, Table 1$)$.

The results of the repeated measures analysis test demonstrated that the mean ALT in the intervention and control groups was not significantly different $(P=0.592)$. 
However, the mean ALT in the times of the first, second, and third month significantly differed from the time before the intervention $(P=0.001)$. The mean ALT in each of the intervention and control groups in the studied times of treatment represented no significant difference $(P=0.996$, Table 2 and Figure $2 \mathrm{~A})$.

Moreover, repeated measures analysis findings revealed no significant difference in the mean AST in the intervention and control groups $(P=0.942)$. The mean AST in the times of the first, second, and third month significantly varied from the time before the intervention $(P<0.001)$. Contrarily, the mean AST in each of the intervention and control groups in the studied times of treatment was not significantly different $(P=0.213$, Table 2 and Figure 2B).

Based on repeated measures ANOVA results and the post hoc test, there was a significant decrease in the mean in the first, second, and third month, which was significantly different from the time before the treatment $(P<0.001)$.

\section{Discussion}

This study aimed to investigate the effect of $P$. harmala seeds on osteoporosis. Traditional treatments are the commonly used methods for diseases in many parts of the world (26,31). According to the results of bone densitometry, the mineral density of the bone in the spine and hip in the intervention and control groups had a significant improvement after the intervention, and their improvements in the intervention group were significantly higher compared to the control group, reflecting the significant effects of $P$. harmala seeds on bone density in patients prone to osteoporosis.
The positive effect of $P$. harmala can be due to the existence of secondary metabolites, especially alkaloids. Previous research showed that $P$. harmala contains high amounts of beta-carboline alkaloids such as harmalol, harmaline, and harmine (33).

The findings of an animal study demonstrated that the $\beta$-carboline alkaloids present in $P$. harmala increase the activity of alkaline phosphatase $(A L P)$ in MC3T3-E1 cells and expand the expression of mRNA, which increases osteoblast markers, including $A L P$ and osteocalcin, and accelerates the mineralization of MC3T3-E1 cells. Additionally, harmine increases the differentiation in primary osteoblasts and stem cells by inducing the expression of the bone morphogenetic protein (BMP) and Runx2 pathways (33-35). Yonezawa et al reported that harmine, which is a compound found in P. harmala, has anabolic effects on osteoblast (34).

Osteocalcin and ALP are two of the most important markers of bone formation, reflecting various aspects of osteoblast function and bone formation. A change in the ALP gene and osteocalcin is an important determinant of bone loss due to age (36). The ALP gene plays an important role in the process of mineralization and regulates the concentration of the extracellular pyrophosphate inhibitor (PPI) via the hydrolysis of PPI, which can inhibit the formation of hydroxyapatite crystals and is required in the process of bone mineralization. Since osteoblasts are a major source of ALP, increasing the expression of the ALP gene and its serum level is an indication of the stimulation of osteoblast cells, and then cellular signaling increases with increased BMD (37). Furthermore, the ALP gene has an essential role in the active metabolism of inorganic phosphate release via the hydrolysis of phosphorus

Table 1. Comparison of bone densitometry results in intervention and control groups

\begin{tabular}{|c|c|c|c|c|}
\hline \multicolumn{2}{|l|}{ Variables } & \multirow{2}{*}{$\begin{array}{c}\begin{array}{c}\text { Intervention group } \\
(\mathbf{n}=\mathbf{5 0}) \\
\text { Mean } \pm \text { SD }\end{array} \\
-2.32 \pm 0.86\end{array}$} & \multirow{2}{*}{$\begin{array}{c}\begin{array}{c}\text { Control group } \\
(\mathbf{n}=\mathbf{5 0})\end{array} \\
\text { Mean } \pm \text { SD }\end{array}$} & \multirow{2}{*}{$\begin{array}{c}\boldsymbol{P}_{\text {value }}{ }^{\mathrm{a}} \\
0.927\end{array}$} \\
\hline \multirow{4}{*}{ BMD of the femur } & Before & & & \\
\hline & Sfter & $-1.88 \pm 0.81$ & $-2.11 \pm 0.89$ & 0.181 \\
\hline & $P$ value $^{\mathrm{b}}$ & $0.000^{* *}$ & $0.000^{* *}$ & \\
\hline & Difference between before and after treatment ${ }^{a}$ & $-0.37 \pm 0.09$ & $-0.24 \pm 0.17$ & $0.000^{* *}$ \\
\hline \multirow{4}{*}{ BMD of the spinal cord } & Before & $-2.46 \pm 0.82$ & $-2.67 \pm 0.66$ & 0.167 \\
\hline & After & $-2.10 \pm 0.82$ & $-2.43 \pm 0.68$ & $0.030^{*}$ \\
\hline & $P$ value $^{b}$ & $0.000^{* *}$ & $0.000^{* *}$ & \\
\hline & Difference between before and after treatment ${ }^{a}$ & $-0.44 \pm 0.12$ & $-0.22 \pm 0.07$ & $0.000^{* *}$ \\
\hline
\end{tabular}

Note. SD: Standard deviation; BMI: Body mass index.

" Significant at $P<0.001 ;{ }^{*}$ Significant at $P<0.05 ;{ }^{\text {a }}$ Independent t-test; ${ }^{\text {b }}$ Paired t-test.

Table 2. Effects of group (control and intervention), time (before, first month, second month, and third month after treatment), and their interaction group*time

\begin{tabular}{|c|c|c|c|c|c|c|c|c|c|}
\hline \multirow{2}{*}{ Scale } & \multicolumn{3}{|c|}{ Group } & \multicolumn{3}{|c|}{ Time } & \multicolumn{3}{|c|}{ Group * Time } \\
\hline & $F$ & df & $P$ & $\mathbf{F}$ & df & $P$ & $F$ & df & $P$ \\
\hline ALT & 0.289 & 1.98 & 0.592 & 6.291 & 3.294 & $0.001^{\mathrm{a}}$ & 0.016 & 3.294 & 0.996 \\
\hline AST & 0.005 & 1.98 & 0.942 & 8.750 & 3.294 & $<0.001^{\mathrm{a}}$ & 1.510 & 3.294 & 0.213 \\
\hline
\end{tabular}

Note. ALT: Alkaline aminotransferase; AST: Aspartate aminotransferase. 

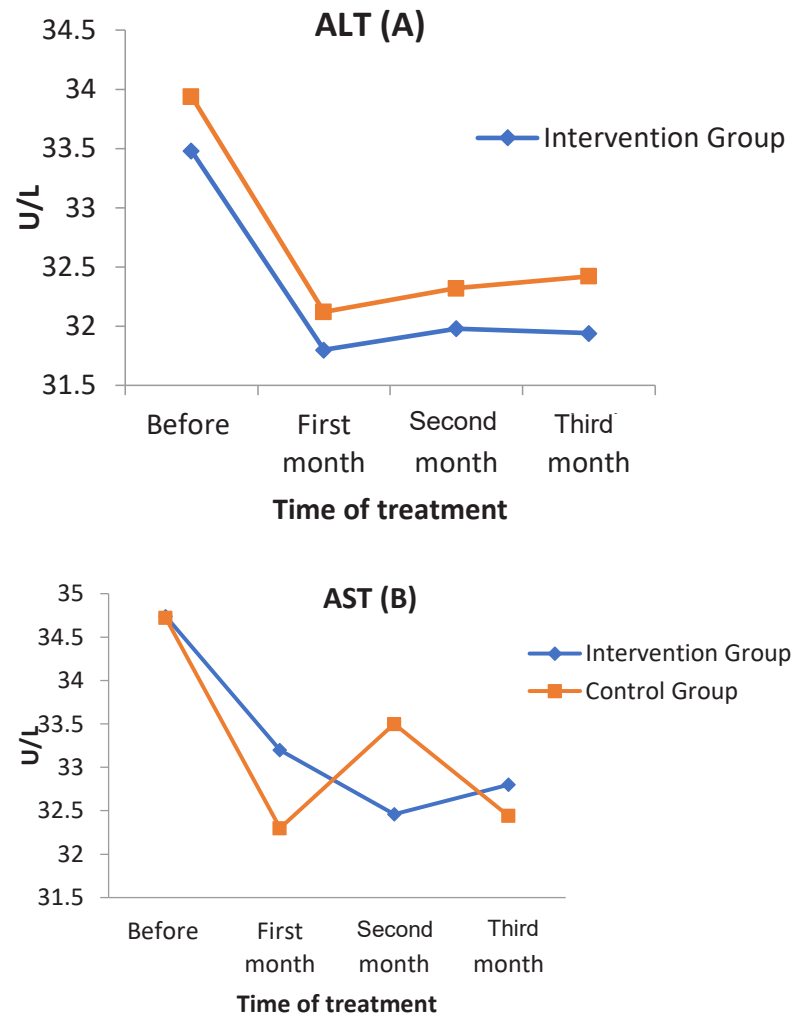

Figure 2. Mean of liver enzymes at the time of interventions (before, first, second, and third month after the treatment) between control and intervention groups. Note. ALT: Alkaline aminotransferase; AST: Aspartate aminotransferase.

components (38).

In a study focusing on determining the mechanism of hormone estrogenic effects in the cell culture, it was reported that the use of the BMP antagonist and its receptor inhibition reduced harmine effects in increasing ALP activity and the growth and differentiation of bone cells (39). Harmine also increases the expression of Runx 2 and Osterix mRNA, which are the main transcription factors in differentiating osteoblasts (40). Harmine treatment activates the receptors of BMP and Runx2 (41). Similarly, it was found that harmonium $(10 \mathrm{mg} / \mathrm{kg}$ ) prevented bone loss in ovariectomized mice with osteoporosis (42). In addition, another study reported that harmine increased the expression of cartilage markers including agricon and COL2 $\alpha 1$, and led to an increase in the primary regulator of chondrogenesis, SOX-9, and chondrogenesis in ATDC5 chondrogenesis in ATDC5 cells (41). Considering that the material of the bone fields contains collagen and cartilage, harmine may increase bone formation and bone density by increasing the production of the cartilage (43).

The study showed that the levels of liver enzymes such as AST and ALT did not changed, Previous histological studies as well indicates liver degeneration does not occur in the rats treated with a dose of $1 \mathrm{~g} / \mathrm{kg}$ (44). Moreover, animal studies confirmed that $P$. harmala do not cause hepatocytotoxicity while the extracts of $P$. harmala are efficient for decreasing AST and ALT activities and bilirubin levels in male rats $(45,46)$ Based on the evidence, harmaline was the most potent compound against hepatocarcinoma and fibrosarcoma $(47,48)$.

The limitations of this study were the lack of the measurement of serum vitamin D levels and exposure to sunlight at the beginning and end of the study. Another limitation was the lack of using a placebo for the control group due to financial restrictions. However, the strength of this clinical trial study was the continuous follow-up of the intervention.

\section{Conclusion}

Overall, the results of this study approved that the use of $P$. harmala, along with a conventional drug improves the bone density of the thigh and spine in postmenopausal women with osteoporosis, which may reduce osteoporosis in postmenopausal women while indicating no hepatic or renal complications. The effects of $P$. harmala on BMD are probably due to its alkaloids of $\beta$-carboline, especially the harmine. These compounds have been shown to improve bone formation in cell culture media and animal models. To the best of our knowledge, the present study was the first one to demonstrate the beneficial effects of spin, including high levels of these compounds. Further studies are needed for more complete results in effect of compounds of Peganum harmala seeds.

Conflict of Interests

There is no conflict of interests.

\section{Ethical Approval}

This study was performed according to the guidelines presented in the Declaration of Helsinki. In addition, the study was approved by the Medical Ethics Committee of Shahrekord University of Medical Sciences (code: IR.SKUMS.REC.1395.33), and its protocol was confirmed by the Iranian Registry of Clinical Trials (identifier: IRCT2017091910222N122). The recommended dosage was regarded safe, namely, it does not harm the liver and kidney function $(49,59)$.

\section{Authors' Contributions}

$\mathrm{MD}, \mathrm{ZKH}$, and FD jointly conceived and designed the study. ZLG and FF supervised the clinical trial, and $\mathrm{MD}, \mathrm{FD}$, and SF supervised orthopedics data analysis. Further, NA and ZKH conducted diagnostic tests, and SF and FM drafted the manuscript. ZLG and SF obtained funding. All authors read and approved the final manuscript.

\section{Funding/Support}

This study was funded by Shahrekord University of Medical Sciences.

\section{Acknowledgments}

This article was obtained from a research project approved at Shahrekord University of Medical Sciences (code: 1029) on 2017.01.17. Hereby, the authors would like to appreciate the financial support of Shahrekord University of Medical Sciences and the unit for the Development of Clinical Research at Ayatollah Kashani Hospital of Shahrekord. 


\section{References}

1. Levy M, Wang MY, Armstrong JK, Fisher TC. Bone Hemostasis Method and Materials. Google Patents; 2017.

2. Elliot-Gibson V, Sale J, Jain R, Bogoch E. Fracture liaison services-Canada. In: Secondary Fracture Prevention. Elsevier; 2019. p. 79-107.

3. Jacome-Galarza CE, Percin GI, Muller JT, Mass E, Lazarov T, Eitler J, et al. Developmental origin, functional maintenance and genetic rescue of osteoclasts. Nature. 2019;568(7753):541-5. doi: 10.1038/s41586-019-1105-7.

4. Ikebuchi Y, Aoki S, Honma M, Hayashi M, Sugamori Y, Khan M, et al. Coupling of bone resorption and formation by RANKL reverse signalling. Nature. 2018;561(7722):195200. doi: 10.1038/s41586-018-0482-7.

5. Tian L, Yang R, Wei L, Liu J, Yang Y, Shao F, et al. Prevalence of osteoporosis and related lifestyle and metabolic factors of postmenopausal women and elderly men: a crosssectional study in Gansu province, Northwestern of China. Medicine (Baltimore). 2017;96(43):e8294. doi: 10.1097/ md.0000000000008294.

6. Rousseau C, Jean S, Gamache P, Lebel S, Mac-Way F, Biertho L, et al. Change in fracture risk and fracture pattern after bariatric surgery: nested case-control study. BMJ. 2016;354:i3794. doi: 10.1136/bmj.i3794.

7. Peng K. Falls and Hip Fractures in Older Chinese: Risk Factors, Burden, and Management [dissertation]. University of Sydney, Faculty of Medicine and Health, School of Public Health; 2019.

8. Ramnemark A, Nilsson M, Borssén B, Gustafson Y. Stroke, a major and increasing risk factor for femoral neck fracture. Stroke. 2000;31(7):1572-7. doi: 10.1161/01.str.31.7.1572

9. Kerr C, Bottomley C, Shingler S, Giangregorio L, de Freitas HM, Patel C, et al. The importance of physical function to people with osteoporosis. Osteoporos Int. 2017;28(5):1597607. doi: 10.1007/s00198-017-3911-9.

10. Fahimfar N, Gharibzadeh S, Khashayar P, Rajabian R, Ranjbar Omrani G, Bahrami A, et al. Iranian Multicenter Osteoporosis Studies (IMOS) during last decade: rationale, main findings, lessons learned and the way forward. J Diabetes Metab Disord. 2020:1-6. doi: 10.1007/s40200-02000600-6.

11. Wright NC, Saag KG, Dawson-Hughes B, Khosla S, Siris ES. The impact of the new National Bone Health Alliance (NBHA) diagnostic criteria on the prevalence of osteoporosis in the USA. Osteoporos Int. 2017;28(4):122532. doi: 10.1007/s00198-016-3865-3.

12. Whitney DG, Alford AI, Devlin MJ, Caird MS, Hurvitz EA, Peterson MD. Adults with cerebral palsy have higher prevalence of fracture compared with adults without cerebral palsy independent of osteoporosis and cardiometabolic diseases. J Bone Miner Res. 2019;34(7):1240-7. doi: 10.1002/jbmr.3694.

13. Black DM, Cauley JA, Wagman R, Ensrud K, Fink HA, Hillier TA, et al. The ability of a single BMD and fracture history assessment to predict fracture over 25 years in postmenopausal women: the study of osteoporotic fractures. J Bone Miner Res. 2018;33(3):389-95. doi: 10.1002/jbmr.3194.

14. Raterman HG, Lems WF. Pharmacological management of osteoporosis in rheumatoid arthritis patients: a review of the literature and practical guide. Drugs Aging. 2019;36(12):1061-72. doi: 10.1007/s40266-019-00714-4.
15. Zhao H, Zhao N, Zheng P, Xu X, Liu M, Luo D, et al. Prevention and treatment of osteoporosis using Chinese medicinal plants: special emphasis on mechanisms of immune modulation. J Immunol Res. 2018;2018:6345857. doi: 10.1155/2018/6345857.

16. Chiavarini M, Naldini G, Fabiani R. The role of diet in osteoporotic fracture healing: a systematic review. Curr Osteoporos Rep. 2020;18(3):138-47. doi: 10.1007/s11914020-00573-8.

17. Liu X, Li M, Tan S, Wang C, Fan S, Huang C. Harmine is an inflammatory inhibitor through the suppression of NF- $\kappa B$ signaling. Biochem Biophys Res Commun. 2017;489(3):332-8. doi: 10.1016/j.bbrc.2017.05.126.

18. Wang KB, Hu X, Li SG, Li XY, Li DH, Bai J, et al. Racemic indole alkaloids from the seeds of Peganum harmala. Fitoterapia. 2018;125:155-60. doi: 10.1016/j. fitote.2018.01.008.

19. Bournine L, Bensalem S, Fatmi S, Bedjou F, Mathieu V, Iguer-Ouada $\mathrm{M}$, et al. Evaluation of the cytotoxic and cytostatic activities of alkaloid extracts from different parts of Peganum harmala L. (Zygophyllaceae). Eur J Integr Med. 2017;9:91-6. doi: 10.1016/j.eujim.2016.10.002.

20. Amidfar M, Réus GZ, Quevedo J, Kim YK, Arbabi M. Effect of co-administration of memantine and sertraline on the antidepressant-like activity and brain-derived neurotrophic factor (BDNF) levels in the rat brain. Brain Res Bull. 2017;128:29-33. doi: 10.1016/j.brainresbull.2016.11.003.

21. Apostolico I, Aliberti L, Caputo L, De Feo V, Fratianni F, Nazzaro F, et al. Chemical composition, antibacterial and phytotoxic activities of Peganum harmala seed essential oils from five different localities in Northern Africa. Molecules. 2016;21(9). doi: 10.3390/molecules21091235.

22. Majid A. A review study of the chemical constituents and therapeutic effects of Peganum harmala L. Global J Pure Appl Chem Res. 2018;6(2):12-9.

23. Shirani-Boroujeni M, Heidari-Soureshjani S, Keivani Hafshejani Z. Impact of oral capsule of Peganum harmala on alleviating urinary symptoms in men with benign prostatic hyperplasia; a randomized clinical trial. J Renal Inj Prev. 2017;6(2):127-31. doi: 10.15171/jrip.2017.25.

24. Akhtar MF, Raza SA, Saleem A, Hamid I, Ashraf Baig MMF, Sharif A, et al. Appraisal of anti-arthritic and anti-inflammatory potential of folkloric medicinal plant Peganum harmala. Endocr Metab Immune Disord Drug Targets. 2021. doi: 10.2174/1871530321666210208211310.

25. Yonezawa T, Hasegawa S, Asai M, Ninomiya T, Sasaki T, Cha BY, et al. Harmine, a $\beta$-carboline alkaloid, inhibits osteoclast differentiation and bone resorption in vitro and in vivo. Eur J Pharmacol. 2011;650(2-3):511-8. doi: 10.1016/j.ejphar.2010.10.048.

26. Kumar K, Wang P, E AS, Khamrui S, Secor C, M BL, et al. Structure-activity relationships and biological evaluation of 7 -substituted harmine analogs for human $\beta$-cell proliferation. Molecules. 2020;25(8):1983. doi: 10.3390/ molecules25081983.

27. Akkawi I, Zmerly H. Osteoporosis: current concepts. Joints. 2018;6(2):122-7. doi: 10.1055/s-0038-1660790.

28. Salamat MR, Salamat AH, Abedi I, Janghorbani M. Relationship between Weight, Body mass index, and bone mineral density in men referred for dual-energy X-ray absorptiometry scan in Isfahan, Iran. J Osteoporos. 2013;2013:205963. doi: 10.1155/2013/205963. 
29. Lee JE, Kim KM, Kim LK, Kim KY, Oh TJ, Moon JH, et al. Comparisons of TBS and lumbar spine BMD in the associations with vertebral fractures according to the T-scores: a cross-sectional observation. Bone. 2017;105:26975. doi: 10.1016/j.bone.2017.09.017.

30. Shevroja E, Koromani F, Leslie WD, Lamy O, Rivadeneira F, Hans D. The utility of tbs-adjusted BMD T-score in the discrimination of the major osteoporotic fractures in the postmenopausal women of the Rotterdam and the OsteoLaus studies. J Clin Densitom. 2018;21(4):610. doi: 10.1016/j.jocd.2018.05.034

31. Zhang ND, Han T, Huang BK, Rahman K, Jiang YP, Xu HT, et al. Traditional Chinese medicine formulas for the treatment of osteoporosis: implication for antiosteoporotic drug discovery. J Ethnopharmacol. 2016;189:61-80. doi: 10.1016/j.jep.2016.05.025.

32. Shahrajabian MH, Sun W, Cheng Q. Improving health benefits with considering traditional and modern health benefits of Peganum harmala. Clin Phytoscience. 2021;7(1):18. doi: 10.1186/s40816-021-00255-7.

33. Ahmed H, Elzahab HA, Alswiai G. Purification of antioxidant protein isolated from Peganum harmala and its protective effect against CCl4 toxicity in rats. Turk J Biol. 2013;37(1):39-48

34. Yonezawa T, Lee JW, Hibino A, Asai M, Hojo H, Cha BY, et al. Harmine promotes osteoblast differentiation through bone morphogenetic protein signaling. Biochem Biophys Res Commun. 2011;409(2):260-5. doi: 10.1016/j. bbrc.2011.05.001.

35. Lim S, Kim JA, Lee T, Lee D, Nam SH, Lim J, et al. Stimulatory effects of KPR-A148 on osteoblast differentiation and bone regeneration. Tissue Eng Regen Med. 2019;16(4):405-13. doi: 10.1007/s13770-019-00200-3.

36. Sogabe N, Tanabe R, Haraikawa M, Maruoka Y, Orimo H, Hosoi T, et al. Associations between serum bone-specific alkaline phosphatase activity, biochemical parameters, and functional polymorphisms of the tissue-nonspecific alkaline phosphatase gene in a Japanese population. Asia Pac J Clin Nutr. 2013;22(1):160-5. doi: 10.6133/apjcn.2013.22.1.11.

37. Vimalraj S. Alkaline phosphatase: structure, expression and its function in bone mineralization. Gene. 2020;754:144855. doi: 10.1016/j.gene.2020.144855.

38. Luo H, Lin X, Li L, Lin L, Zhang C, Lin S. Transcriptomic and physiological analyses of the dinoflagellate Karenia mikimotoi reveal non-alkaline phosphatase-based molecular machinery of ATP utilisation. Environ Microbiol. 2017;19(11):4506-18. doi: 10.1111/1462-2920.13899.

39. Kim M, Kang JH, Oh GH, Park MH. Ishige sinicola extract stimulates osteoblast proliferation and differentiation via the bone morphogenetic protein 2/runt-related gene 2 signalling pathway. Z Naturforsch C J Biosci. 2019;74(78):167-74. doi: 10.1515/znc-2018-0044.

40. Zhang B, Zhang X, Xiao J, Zhou X, Chen Y, Gao C. Neuropeptide Y upregulates Runx2 and osterix and enhances osteogenesis in mouse MC3T3-E1 cells via an autocrine mechanism. Mol Med Rep. 2020;22(5):4376-82. doi: 10.3892/mmr.2020.11506.

41. Lim HC, Cha BY, Song SU, Yun JH. Harmine promotes periodontal ligament cell-induced tissue regeneration. Oral Dis. 2018;24(3):456-64. doi: 10.1111/odi.12770.

42. Huang J, Yin H, Rao SS, Xie PL, Cao X, Rao T, et al. Harmine enhances type $\mathrm{H}$ vessel formation and prevents bone loss in ovariectomized mice. Theranostics. 2018;8(9):2435-46. doi: 10.7150/thno.22144.

43. Huang J, Li YY, Xia K, Wang YY, Chen CY, Chen ML, et al. Harmine targets inhibitor of DNA binding- 2 and activator protein-1 to promote preosteoclast PDGF-BB production. J Cell Mol Med. 2021;25(12):5525-33. doi: 10.1111/ jcmm.16562.

44. Lamchouri F, Settaf A, Cherrah Y, El Hamidi M, Tligui N, Lyoussi B, et al. Experimental toxicity of Peganum harmala seeds. Ann Pharm Fr. 2002;60(2):123-9.

45. Hamden K, Masmoudi H, Ellouz F, ElFeki A, Carreau S. Protective effects of Peganum harmala extracts on thiourea-induced diseases in adult male rat. J Environ Biol. 2008;29(1):73-7.

46. Asgarpanah J, Ramezanloo F. Chemistry, pharmacology and medicinal properties of Peganum harmala L. Afr J Pharm Pharmacol. 2012;6(22):1573-80. doi: 10.5897/ ajpp11.876.

47. Boeira JM, da Silva J, Erdtmann B, Henriques JA. Genotoxic effects of the alkaloids harman and harmine assessed by comet assay and chromosome aberration test in mammalian cells in vitro. Pharmacol Toxicol. 2001;89(6):287-94. doi: 10.1034/j.1600-0773.2001.d01-162.x.

48. Cao R, Chen H, Peng W, Ma Y, Hou X, Guan H, et al. Design, synthesis and in vitro and in vivo antitumor activities of novel beta-carboline derivatives. Eur J Med Chem. 2005;40(10):991-1001. doi: 10.1016/j.ejmech.2005.04.008.

49. Mahmoudian M, Jalipour H, Salehian Dardashti P. Toxicity of Peganum harmala: review and a case report. Iran J Pharmacol Ther. 2002;1(1):1-0.

50. Moloudizargari M, Mikaili P, Aghajanshakeri S, Asghari $\mathrm{MH}$, Shayegh J. Pharmacological and therapeutic effects of Peganum harmala and its main alkaloids. Pharmacogn Rev. 2013;7(14):199-212. doi: 10.4103/0973-7847.120524. 